\title{
BACON Y LOS PROYECTOS DE LENGUAJE FILOSÓFICO DEL SIGLO XVII
}

Pilar CASTRILLO.

Dpto. de Lógica. UNED

1.

A mediados del siglo XVII diversos estudiosos tanto de las Islas Británicas como del Continente -especialmente de Francia- se embarcaron en la búsqueda de lenguajes filosóficos, esto es, de sistemas de símbolos que, además de estar libres de ambigüedad, fueran un reflejo de las propiedades de los objetos significados. La intención que animaba a cuantos se involucraron en semejante empresa, que alcanzó su culminación en el Essay toward a Real Character and a Philosophical Language de John Wilkins, era construir un lenguaje que no sólo evitara las imperfecciones de los lenguajes naturales y sirviera de medio de comunicación entre hombres de diferentes comunidades linguísticas, sino que también fuera apto para clasificar ideas y datos de los fenómenos naturales y, en esa medida, sirviera de instrumento a través del cual conseguir conocimiento del mundo real. Se partía de la base de que semejante meta sólo sería alcanzable si el lenguaje en cuestión, además de ser más simple, más breve y por ende más fácil de aprender y usar que cualquiera de los lenguajes existentes, lograba reflejar en la composición de sus "palabras" las diversas cualidades de las cosas naturales y sus relaciones entre ellas. Hoy en día este tipo de proyectos, de cuya importancia y popularidad da fe el hecho de

Endoxa: Series Filosoficas, $n^{\circ} 6,1995$, UNED, Madrid:

Pilar Castrillo : Bacon y los proyectos de lenguaje filosófico del s. XVII. pp. 181-211. 
que fueran objeto de consideración por parte de mentes tan preclaras como Descartes, Mersenne, Boyle, Newton, Wilkins y Leibniz - por no mencionar sino algunas de las más importantestienden a ser considerados como reliquias del pasado, curiosidades lingüísticas carentes por completo de interés. Tales proyectos, sin embargo, además de suponer un compendio de muchas de las ideas que sobre el lenguaje se habían ido forjando desde el Renacimiento y de contener interesantes sugerencias acerca de la construcción de una gramática "universal", revisten un interés adicional: en ellos nos es dado contemplar la transformación de ciertas formas medievales y renacentistas de pensar la realidad en otras aparentemente más científicas, pero en el fondo no mucho mejor fundadas que aquéllas.

No es posible entender este movimiento de los lenguajes universales, que aparece vinculado al nacimiento de la ciencia moderna, sin tener en cuenta la atmósfera cultural en la que se gestó o sin tomar en consideración las presupuestos y fines perseguidos por los creadores de los diversos proyectos, por extraños que ahora puedan resultarnos. Así, no podremos entenderlo, como tampoco el problema de la clasificación sistemática del saber, tan estrechamente vinculado a tales proyectos, sin analizar, por ejemplo, su vinculación con las discusiones que sobre el arte de la memoria y el papel de ésta habían venido manteniendo durante mucho tiempo estudiosos de muy distinto pelaje; tampoco podremos entenderlo si renunciamos a tomar en consideración los intentos de sistematización y simbolización del saber humano que habian sido llevados a cabo por la Cábala y el lulismo o sin tener presente los proyectos de reforma educativa a los que están inextricablemente unidos. En una palabra, no podremos entenderlo si tratamos de analizarlo proyectando nuestras categorías y problemas actuales y si nos resistimos a no ver en el pasado otra cosa que una instancia confirmatoria del presente.

Aunque las primeras contribuciones que conforman este movimiento se producen en suelo francés en unas circunstancias no demasiado bien conocidas aún, lo cierto es que el grueso de 
estos proyectos de lenguaje filosófico fue obra de un grupo de estudiosos directa o indirectamente vinculados a la comunidad científica de Oxford que constituyó el germen de lo que luego sería la Royal Society londinense ${ }^{1}$. No es difícil ver que en el ambiente cultural de las Islas Británicas de aquel momento confluían diversos factores que lo hacian especialmente propicio para el desarrollo de semejante tipo de construcciones: la invención de la taquigrafía, el interés por los códigos, lenguajes cifrados y métodos de comunicación a distancia, que se vieron fomentados por la explosión de una guerra civil entre dos bandos que hablaban una misma lengua, el renacimiento del interés por los métodos de organización del conocimiento diseñados por el lulismo y la Cábala, no son sino algunos de los más destacados. Determinar hasta qué punto el surgimiento y desarrollo de semejantes proyectos se produce de un modo más o menos espontáneo en el citado ambiente o es preciso postular fuentes de inspiración más concretas que expliquen el auge de los mismos es una cuestión bastante compleja y que requiere estudios más documentados y detallados de los ahora disponibles, cuestión a cuyo esclarecimiento quisiera contribuir analizando el grado de responsabilidad de la obra baconiana en la aurora de este movimiento, que muy bien pudiera ocurrir que tuviera además otras fuentes de inspiración.

Aunque el propósito abiertamente confesado por algunos de los principales representantes involucrados en este movimiento, como es el caso de Seth Ward, George Dalgarno y John Wilkins, es el de

\footnotetext{
1 Para una panorámica de este movimiento tanto en Inglaterra como en Francia, con algunas incursiones en el siglo XVIII, Cf.J. Knowlson, Universal Language Schemes in England and France 1600-1800 (Toronto University Press, 1975). También resultan de gran utilidad varios de los artículos reunidos por Vivian Salmon en su The Study of Language in Seventeenth Century England, (Amsterdam, John Benjamins, 1979), así como P. Rossi, Clavis Universalis (FCE, 1989; publicado en 1960), que considera los sistemas de lenguaje universal del siglo XVII como una continuación de la búsqueda de un ars combinatoria en épocas anteriores. En cuanto al libro de Paul E. Cornelius, Languages in Seventeenth and Early Eighteenth Century Imaginary Voyages (Geneva, 1965) al centrarse en el análisis de como los viajes imaginarios fueron la fuente de lenguajes imaginarios, tienen un interés más limitado.
} 
pergeñar un instrumento de conocimiento de la realidad natural a partir del lenguaje construido, el hecho de que la mayoría de ellos aludan en uno u otro lugar de sus obras a la confusión de lenguas en Babel y manifiesten su convicción de que sus construcciones servirán para poner remedio a semejante situación llevó a alguno de los que primero se interesaron por el estudio de este tema a mantener la tesis de que el estímulo para semejante empresa no fue otro que el deseo de contribuir a la unidad de las Iglesias de Europa, que se habría visto resquebrajada por causa de la ambigüedad verbal subyacente a las disputas religiosas ${ }^{2}$. De acuerdo con semejante tesis acerca de los orígenes de este movimiento, la búsqueda de lenguajes universales perfectos tuvo como fuente de inspiración directa las ideas del reformista checo Johann Amos Komensky (Comenius), que habrían sido hechas circular entre los constructores de semejantes esquemas por su común amigo Samuel Hartlib, en manos del cual aquél habría dejado, tras su estancia en Inglaterra en 1641-42, el manuscrito de lo que luego sería su Via lucis. El argumento principal esgrimido en favor de

\footnotetext{
${ }^{2}$ Cf.por ejemplo, B. De Mott, "The Sources and Development of John Wilkins' "Philosophical Language" ", Journal of English and German Philology 1958. Esta tesis de la influencia de Comenius en los constructores de lenguajes perfectos ya había sido defendida por este autor en "Comenius and the Real Character of England", PMLA 70(1955), 1068-1081. Para críticas a la misma véase Otto Funcke, "On the Sources of John Wilkin's Philosophical Language 1668", ES (1959), pp. 208-14 y Vivian Salmon, "Language-Planning in Seventeenth Century, its context and aims", publicado en 1966 y recogido en The Study of Language in Seventeenth Century England, pp. 129-157. Salmon sugiere, como luego veremos, que tanto Comenius como Wilkins se inspiran en una misma fuente común, Marin Mersenne y su Harmonie Universelle.

${ }^{3}$ El alemán Samuel Hartlib llegó a Inglaterra como simple comerciante pero enseguida se interesó por la ciencia, haciéndose amigo de algunos de los científicos más importantes de la época y aglutinando en torno a sí a algunas de las figuras más prestigiosas del momento. Hartlib dejó numerosos manuscritos que contienen ideas sobre la reforma y enseñanza del lenguaje. Estas son especialmente frecuentes en su cuaderno de notas Ephemerides. En el ingente trabajo realizado por Charles Webster, The Great Instauration: science, medicine and reform 1626-60 (London, Duckworth, 1975), en que se estudian las relaciones entre el puritanismo y el desarrollo científico durante esta época, se presenta a Hartlib como un entusiasta de la reforma baconiana interpretada como movimiento religioso. Para las relaciones de Hartlib con Comenius, Cf. George $\mathrm{H}$. Turnbull, Hartlib, Dury and Comenius (Liverpool, 1947).
} 
esta influencia de Comenius en los constructores de lenguajes universales británicos no es otro que el de que es precisamente después de esta visita suya a Inglaterra cuando el mero interés por la construcción de vocabularios básicos en lenguas ya existentes se transforma en una búsqueda de nuevos lenguajes basados en clasificaciones científicas de la realidad natural. De todos es sabido, sin embargo, que el razonar post hoc ergo propter hoc es una forma ilegítima de razonar, por lo que esta hipótesis en pro de la influencia de Comenius y de su ideal pansófico en este movimiento de búsqueda de un medio internacional de comunicación no pasa de ser una simple conjetura a menos que pueda esgrirse a su favor algún otro elemento de juicio además de éste. Ahora bien, es obvio que si los constructores de lenguajes perfectos se hubieran sentido en deuda con las observaciones que a propósito de «un lenguaje absolutamente nuevo, absolutamente fácil, absolutamente racional, en suma un lenguaje pansófico, el portador universal de Luz» hace Comenius en su Via lucis $^{4}$-que por cierto no se publicó hasta el año 1668, esto es, el mismo año que el Essay de Wilkins- encontraríamos en sus obras referencias a las mismas y a su creencia en que mediante la conquista del ideal pansófico podrían desaparecer las disputas, las guerras y la falta de comunicación entre las gentes. Mas éste dista mucho de ser el caso, ya que, si bien en los escritos de Seth Ward, George Dalgarno y Cave Beck se alude a Comenius, la referencia es siempre a su influyente tratado sobre la enseñanza del latín, Janua linguarum reserata, y nunca a sus ideas acerca del lenguaje filosófico. Cierto que muchos de estos autores no se mostraron igual de reticentes a la hora de reconocer las motivaciones religiosas que también subyacen a su trabajo, y que entre las utilidades de su lenguaje menciona George Dalgarno en su Ars signorum «la civilización de las naciones bárbaras, la propagación del Evangelio y el incremento del tráfico y el comercio»", y John Wilkins, la de «llevar a la propagación del

The Way of Light, traduc. de E.T. Campagnac, London, 1938, p. 8.

5 Ars signorum, London, 1661, ed. facsímil, Menston 1968, «Carta de Recomen- 
conocimiento de la Religión ${ }^{6}$, pero esto parece deberse únicamente a la necesidad que muchos de ellos sintieron de justificar su ocupación, dado el cargo éclesiástico que ocupaban.

Pero si ninguno de los creadores de lenguajes universales reconoce su deuda para con Comenius y su Via lucis, cuyo manuscrito no es ni siquiera seguro que conocieran, y si la idea de crear un lenguaje de signos que tuvieran la virtud de denotar las propiedades de las cosas no se originó en el Via Lucis de Comenius, ¿de dónde pudo surgir semejante idea? Los datos de que hoy disponemos parecen confirmar que la primera propuesta de construir un lenguaje universal que propiciara la difusión del conocimiento humano es obra del filósofo francés Mersenne, quien en su Harmonie universelle, publicada en 1636, pero acabada unos años antes, sugiere ya la idea de un lenguaje basado en la ordenación de conceptos conforme a género, especie y diferencia ${ }^{7}$. Sin embargo, aunque no es imposible rastrear posibles relaciones entre él y algunos de los constructores ingleses de lenguajes universales a través de contactos tales como sus discusiones con William Petty o su correspondencia con Theodore Haak o con el propio Samuel Hartlib, lo cierto es que ninguno de ellos reconoce tampoco su deuda para con Mersenne en este punto. ${ }^{8}$ En cambio,

dación"n.

6 J. Wilkins, An Essay towards a Real Character and a Philosophical Language, 1668, ed. facsímil, Menston Yorks, 1968, "Epistola Dedicatoria».

7 Parece que es a Marsenne a quien corresponde el honor de haber sido el primer estudioso europeo en sugerir la importancia de un lenguaje universal para el avance del saber, toda vez que ya en octubre de 1629 habia recibido permiso de su orden para la publicación de su Harmonie universelle, en la que expone estas ideas. A pesar de ello, este interesante aspecto de su obra ha recibido aún muy poca atención. Salmon (op. cit.) ha defendido convincentemente la tesis de que M. Mersenne fue posiblemente la fuente más directa de las primeras ideas de Wilkins. Posterior evidencia ha sido aducida por Aarsleff para mostrar que Wilkins está en deuda con Mersenne no sólo en este punto, sino en algunas otras de las ideas defendidas en sus primeros escritos. Cf. "Wilkins", Dictionary of Scientiphic Biography XIV, pp. 361-81.

' Sería difícil exagerar la importancia de la figura de Mersenne como corresponsal de algunos de los representantes más destacados de la cultura europea del momento. Entre los ingleses estaban, además de William Petty, a quien conocía a través de John Pell, profesor de matemáticas de Amsterdam, y 
todos ellos se muestran preocupados por la cuestión de la ambigüedad y oscuridad de las palabras, todos señalan las insuficiencias de los lenguajes existentes como medios de expresión del conocimiento y todos aluden explícitamente a Bacon como fuente de inspiración de sus ideas en relación con estos temas. Por eso, aunque sería un tanto absurdo postular una única vía por la que esta idea entró en la cultura europea del siglo XVII, sería igual de irrazonable pasar por alto el hecho de que, al plantear algunos de los problemas semánticos para tratar de solucionar los cuales se idearon estos lenguajes, Bacon fue sin lugar a dudas una de las más significativas.

2.

Francis Bacon es una de esas figuras cuyo lugar en la historia del pensamiento se ha visto distorsionado por quienes, en vez de analizar sus raíces en el pasado, se han empeñado en no ver en él más que a un precursor de ideas futuras y más en concreto de una concepción no muy adecuada del método científico. Por fortuna, en estos últimos tiempos han aparecido algunos estudios que, adoptando un enfoque más fructífero, han tratado de ver a Bacon como una figura que emerge de la tradición mágico-hermética del Renacimiento y que a la vez está ansiosa por desmarcarse de lo que para él no eran sino formas extremas y peligrosas de dicha tradición. El caso más notorio lo constituye Francis Bacon, del historiador italiano Paolo Rossi, significativamente subtitulado De la magia a la ciencia'. En este libro, P. Rossi arguye convincentemente que la insistencia de Bacon en la tecnología y en el papel del hombre como manipulador de la naturaleza no pueden

de Theodore Haak, el instigador de las reuniones de Londres que culminarian en la creación de la Royal Society, T. Hobbes, E. Digby y S. Hartlib, entre otros.

${ }^{9}$ El libro es del año 1974. Hay versión española en Alianza Ed., 1990. 
separarse de la tradición hermética renacentista en la que la magia y la técnica se hallaban inextricablemente mezcladas. Y ello a pesar de lo mucho que este autor se preocupa de marcar las distancias que separan a su ideal de hombre de ciencia del orgulloso mago renacentista. Lo que $P$. Rossi viene a mostrar en su libro, gracias a la adopción de este enfoque, es que, aunque en su configuración de la ciencia como poder y del hombre como detentador de tal poder, el gran Verulamio se inspira en la figura del mago, a la vez sustituye la vieja concepción del mago por una visión del científico que puede reconocerse como moderna, esto es, que Bacon es a la vez un continuador de la tradición hermética y un hombre que reacciona contra ella, un hombre que desaprueba semejante tradición, pero que a la vez emerge de ella.

No es ésta, empero, la única tradición renacentista contra el transfondo de la cual se impone considerar la figura del gran Verulamio si se quiere entender su pensamiento y no meramente proyectar en él nuestros propios problemas. Además del "saber fantástico", encarnado por la tradición mágico-hermética, entre las tradiciones cercanas a su tiempo que a sus ojos constituían un obstáculo al avance del saber, Bacon incluye también el "saber contencioso" y el "saber delicado", representados por las corrientes escolástica y humanista, respectivamente. La beligerante actitud de que hace gala hacia esta última, un tipo de saber «más preocupado por las palabras que por el contenido", totalmente explicable si se tiene en cuenta que su propósito era el de sustituir una cultura de tipo retórico-literario por otra de carácter científico-técnico, no debe, sin embargo, llamarnos al engaño de descartar a priori la posible deuda de su pensamiento para con ella. Una mirada atenta a la obra baconiana pone de manifiesto que, a pesar de que toda ella, pero especialmente el Novum Organum, se presenta como una reacción contra la lógica de su tiempo, muchos de los planteamientos y discusiones realizados con la intención de reformar esta lógica, reflejan claros nexos conceptuales con esta corriente de pensamiento contra la que, por otra parte, no deja de rebelarse. Su caracterización y crítica de la filosofía escolástica, la división que 
hace de la lógica en invención y juicio, la unificación que propone del estudio de la invención, su énfasis en la importancia de la dialéctica para la organización y disposición del discurso son, en efecto, algunos de los muchos aspectos que ponen de manifiesto las estrechas afinidades entre su pensamiento y esa tradición humanista contra la que a la vez reacciona, al no ver en ella sino la encarnación de una filosofía fucata et mollis no muy de su gusto.

No es extraño por otra parte que existan tales afinidades: en los programas educativos de inspiración humanista, como el que, entre los años 1573-75, siguió Bacon en la universidad de Cambridge, el estudio del discurso racionalmente construido - lo que en la época se denominaba ars disserendi- ocupaba una muy buena parte de los contenidos de los planes de estudio. Esta dialéctica recordaba ya muy poco a los complejos sistemas lógico-semánticos construidos por los escolásticos tardíos, no tanto porque prescindía de los aspectos más técnicos y abstrusos de los mismos cuanto porque introducía un importante cambio de énfasis: Los dialécticos renacentistas enfatizaron sobre todo las virtudes prácticas de la dialéctica como medio de organizar y disponer la materia de un discurso, asignándole un claro papel utilitario que entre los escolásticos no tenía. Esto les llevó a cambiar también el foco de interés: en lugar de centrarse en el silogismo, como habían hecho aquéllos, resaltaron la importancia de la invención y la disposición de un abanico de tópicos para el discurso. Una consecuencia que se siguió de este cambio de énfasis es que desapareció la línea de demarcación existente entre la lógica entendida como ciencia de la demostración y la dialéctica o el estudio de los modos no demostrativos de argumentar. Por otra parte, este fenómeno confluye en el Renacimiento inglés con otro no menos importante: el extraordinario auge que experimenta la tradición de la retórica clásica, como consecuencia de las profundas transformaciones que estaba experimentando la sociedad inglesa y de la importancia que en ella llegaron a adquirir los debates parlamentarios y las controversias religiosas. 
La repercusión que todos estos cambios tienen en la gestación del pensamiento baconiano y el grado en que este pensamiento hunde sus raíces en la tradición humanista son, como me propongo hacer ver, mucho mayores de lo que su actitud de rechazo hacia la misma pudiera en principio hacernos pensar. Pero, de igual modo que, como pone de manifiesto el estudio de P. Rossi, el identificar las raíces herméticas del pensamiento de Bacon no hace de él un simple representante de esta tradición renacentista ni merma un ápice la importancia histórica de su pensamiento, el rastrear en él puntos de confluencia con la tradición lógico-retórica humanista no obliga tampoco a perder de vista el hecho de que algunas de sus más fértiles ideas, como es el caso de buena parte de las que había de aportar a la constitución de una nueva imagen del conocimiento científico, se modelaron en dura polémica contra ella. Es más, es precisamente visto así, a la vez como un continuador de las tradiciones del Renacimiento y como un opositor a ellas, como Bacon se nos aparece como la figura clave de la historia del pensamiento que es, como una figura en la que se pueden estudiar algunas de las transformaciones que sufren ciertos temas del Renacimiento hasta trocarse en ideas que reaparecen en el siglo XVII revestidas de un ropaje enteramente distinto.

Uno de tales temas es éste de la búsqueda de una característica filosófica o de un lenguaje universal compuesto de "caracteres reales", que Bacon consideraba vinculada al avance de la ciencia. Ya he señalado cómo la mayor parte de los teóricos que en el siglo XVII trabajaron en el intento de elaborar lenguas características con objeto de evitar los inconvenientes e imperfecciones del lenguaje natural citan a este autor como fuente de inspiración de esta idea, pero ¿cómo llegó a ella el propio Bacon?, ¿de qué fuentes se nutre el pensamiento del Lord Canciller en este punto? Para poder responder a estas preguntas no hay más remedio que empezar por pasar revista a algunas de las tesis por él mantenidas, especialmente en The Advancement of Learning y en De dignitate et augmentis scientiarum, acerca del arte de la comunicación y de los signos que la hacen posible, pues éste es el contexto en el que aparece 
defendida esta idea de la conveniencia de construir un lenguaje de caracteres reales que tanta repercusión había de tener medio siglo después.

3.

La tesis de que el saber ha de traducirse en resultados prácticos, de que el conocimiento tiene que servir para aliviar la condición humana es, como tantas veces se ha señalado, una idea recurrente en el pensamiento baconiano. De ella hará el Lord Canciller el fundamento mismo para la evaluación y crítica de las filosofías del pasado. «Entre los signos», escribe en el Novum Organum ${ }^{10}$, «no hay ninguno más noble o más firme que el de los frutos, pues los frutos y las operaciones descubiertas son garantes y fiadores de la verdad de las filosofías». De entre estas filosofías, la que peor parada va a salir de la confrontación con este criterio de evaluación será la filosofía escolástica, «fértil en controversias pero estéril en obras", y a su caracterización y crítica dedicará Bacon muchas de las páginas de sus obras desde su temprano Partus Temporis Masculus. páginas a las que no hace falta prestar demasiada atención para reparar en que los temas presentes en ellas son los mismos que vemos recorrer el pensamiento humanista desde Petrarca hasta Petrus Ramus. Estos no son otros que los de la falta de operatividad de la filosofía escolástica, el agotamiento de sus investigaciones lógicas en una serie de distinciones que no llegan a transformarse en instrumentos cognoscitivos válidos y en medios para realizar operaciones en la realidad natural, la esterilidad, en suma, de sus cavilaciones ${ }^{11}$. Sin embargo, a poco que nos paremos

${ }^{10}$ Nooum Organum I, 73. Siempre que aluda a las obras de Bacon, lo haré a la edición de J. Spedding, R.L. Ellis y D.D. Heath, The Works of Francis Bacon, 14 vols. 1857-1874, ed. facsímil, New York, 1968. En el caso del NO citaré, como es usual, libro y parágrafo; en los demás, por el volumen y página.

"Para la valoración y crítica que Bacon hace de la Escolástica, véase, por 
a analizar estos textos, veremos enseguida que la falta de utilidad que Bacon echa en falta en la filosofía escolástica no es la misma que aquella en la que tiene su origen la crítica humanista. Y es que, mientras que lo que los humanistas objetaban a la lógica escolástica era su falta de utilidad para producir argumentos, la esterilidad de la lógica que a Bacon le preocupa es más bien la relacionada con la producción de artes o ciencias, toda vez que él no cree que una lógica productiva de argumentos sea más rentable que la lógica silogística escolástica a la hora de generar lo que de verdad importa: el conocimiento de la realidad. En efecto, la tarea que Bacon se propone y a la que convoca en el Prefacio a la Instauratio Magna no es sino la de tratar de adquirir conocimiento verdadero de la naturaleza. Esta tarea exigía, por una parte, un registro y recopilación de los fenómenos, y por otra, un método o interpretatio naturae capaz de llevar a los axiomas últimos. Por eso, pese a la presencia en su pensamiento de estos temas y planteamientos procedentes de la tradición humanista, no deja de detectar en la dialéctica forjada dentro de ella los mismos males que aquejaban a la lógica escolástica. En su Instauratio Magna podemos leer, en efecto,

La lógica actualmente en uso, aunque sea muy útil en los escritos civiles y en las artes que se asientan sobre el lenguaje y la opinión vulgares es incapaz con mucho, sin embargo, de tocar la sutilidad de la naturaleza; tratando de asir lo que no comprende sirve más bien para establecer y casi fijar los errores que para abrir la vía a la verdad.

Pero si la reforma de la lógica llevada a cabo por los humanistas distaba mucho de satisfacer las expectativas respecto de lo que, por lo demás, para Bacon no era sino una parte del proyecto general de reforma del conocimiento que se proponía realizar, la

ejemplo, Works, III, 285-87, N. O., I, 89, 121. 
idea de lógica por él defendida sí que guarda muchas afinidades con la mantenida por aquéllos.

La primera cosa en la que se pueden detectar puntos en común con las doctrinas formuladas por los dialécticos humanistas es en la división de la lógica introducida en el Avance del saber y en su versión latina De dignitate et augmentis scientiarum. En ellas establece Bacon que la lógica se divide en cuatro partes conforme a los fines o propósitos que se propone alcanzar. Estos no son otros, en su opinión, que 1) encontrar lo que se busca, 2) enjuiciar lo encontrado, 3) conservar lo enjuiciado y 4) transmitir lo conservado, y las artes resultantes son la investigación o invención, el examen o juicio, la conservación o memoria y la comunicación o transmisión ${ }^{12}$.

La idea de que la lógica ha de ocuparse de los procedimientos de invención y disposición o juicio constituye uno de los signos distintivos de la dialéctica humanista. Esta idea, popularizada por Cicerón, había sido retomada en el Renacimiento por R. Agrícola - una de las figuras más importantes del humanismo centroeuropeo- en su influyente tratado De inventione dialectira. En esta obra, como el título de la misma deja ya entrever, lo q 1e su autor se había propuesto era hacer de los tópicos o de la teoría de la invención el núcleo mismo de la lógica ${ }^{13}$, cosa que, por lo demás, ya habían hecho Cicerón y Quintiliano, las fuentes principales de las que se nutre su pensamiento. Bacon, que es muy posible que se hubiera familiarizado con el tratado de Agricola a su paso por la universidad de Cambridge, no sólo se hace eco de esta división

\footnotetext{
12 Works, III, 383-84.

${ }^{13}$ La versión canónica de este tratado es la realizada por su discípulo Alardus (Cologne, 1539, reimp. Niewkoop, 1967). Sobre la enorme influencia de esta obra y su implantación en diversas universidades alemanas, véase W.J. Ong, Ramus and Talon Inventory (Cambridge, MA, 1988), pp. 534-58, y T. Heath, «Logical Grammar, Grammatical Logic and Humanism in three German Universities», Studies in the Renaissance 18 (1971): 9-64. Una panorámica del desarrollo de la logica dentro de esta corriente de pensamiento puede verse en L. Jardine, "Humanistic Logic", en The Cambridge History of Renaissance Philosophy (Cambridge, University Press, 1988), pp. 173-199, y en P. Castrillo, «El impacto del humanismo renacentista en la concepción de la lógica", Endoxa 5 (1995): 91-115.
} 
de la lógica en invención y juicio, sino que, además, sitúa también la parte dedicada a la disposición o juicio por detrás del arte de la invención, por entender que no tiene ningún sentido hablar de reglas del discurso antes de disponer del material argumentativo pertinente, esto es, antes de ocuparse del arte de la invención ${ }^{14}$.

Hay, sin embargo, un importante aspecto de esta cuestión que Bacon contempla de una forma un tanto distinta a como lo habían hecho los representantes de esta tradición humanista: él cree que el arte de inventar argumentos, en la medida en que no estriba más que en extraer con destreza del patrimonio de conocimientos lo que resulta pertinente para el tema en discusión, no es propiamente una invención, «toda vez que inventar es descubrir lo que no conocemos, no recuperar lo que ya conocemos" ${ }^{15}$. Uno de los temas que se repiten en la obra baconiana es, en efecto, el de la tajante distinción existente entre la invención de argumentos y la invención de artes y ciencias ${ }^{16}$, campo éste último que no fue cultivado por los lógicos ingleses hasta finales del siglo XVI, que es cuando, como consecuencia del resurgimiento del aristotelismo, empieza a aflorar entre ellos un interés por este tipo de temas y problemas que en el Continente, especialmente en Italia, llevaban ya bastante tiempo discutiéndose ${ }^{17}$.

Esta emergencia del aristotelismo coincide en el tiempo con el enorme impacto producido por las ideas de Petrus Ramus en el

\footnotetext{
${ }^{14}$ En los estatutos de 1560 del Trinity College de Cambridge, del que Bacon fue alumno, se especificaban como textos básicos para el estudio de la lógica el tratado de Agrícola y el de Seton, de contenido y orientación muy similares. Cf. L. Jardine, Francis Bacon. Discovery and the Art of Discourse (Cambridge, 1974), p. 9. Véase también, de la misma autora, "The Place of Dialectic Teaching in Sixteenth Century", en Studies in the Renaissance 21 (1974):31-62.

${ }^{15}$ Works III, 384; IV, 421-22.

${ }^{16}$ Works, IV, 407-408.

${ }^{17}$ Para ver el auge experimentado por el aristotelismo en Inglaterra durante la segunda mitad del siglo XVI, véase C.B. Schmitt, John Case and aristotelianism in Renaissance England (Ringston, Ontario, 1983). Esta obra incluye un apéndice de las obras de logica impresas en suelo inglés durante este periodo, que permite formarse una idea general de la fortuna corrida por esta disciplina. (Ibid., Pp. 225229).
} 
pensamiento inglés, especialmente a partir de 1574 , fecha en que se publican sus Dialecticae, tanto en versión latina como en versión inglesa ${ }^{18}$. La pugna entre estos dos paradigmas dará lugar en Cambridge, donde la influencia del ramismo fue mayor, a una serie de controversias y discusiones a las que no se ha prestado hasta la fecha la atención merecida, habida cuenta de que no sólo pueden considerarse responsables del enorme incremento, tanto en cantidad como en calidad, experimentado por la producción lógica en este final de la época isabelina, sino que además constituyen el contexto cultural en el que emergió una figura de la talla de Francis Bacon. De entre estas controversias la más importante y la que más influencia había de ejercer en el pensamiento de nuestro autor es la que tuvo lugar entre E. Digby, uno de los aristotélicos más importantes de este período, y W. Temple, un claro defensor de la postura de P. Ramus, a propósito de la cuestión de si, como éste pretendía, había un solo método adecuado o más bien, como había mantenido Aristóteles, cabía hablar de varios ${ }^{19}$. No es éste el lugar apropiado para analizar la postura mantenida por Bacon en esta controversia ni tampoco el de valorar la influencia que en su idea del método ejercieron las teorías de Ramus, pese a las descalificaciones a que somete su obra, pero sí el de resaltar hasta qué punto sus teorías acerca de la naturaleza y composición de la lógica son deudoras de las ideas reformistas introducidas por aquée ${ }^{20}$.

${ }^{18} \mathrm{La}$ influencia de Ramus en el pensamiento inglés se analiza con todo detalle en W.S. Howell, Logic and Rhetoric in England 1500-1700 (Princeton, 1956) pp. 173281.

${ }^{19}$ De los pormenores de la misma se da cuenta en N.W. Gilbert, Renaissance Concepts of Method, New York, 1960, pp. 200-209, J. Freudenthal, «Beiträge zur Geschichte der Englischen Philosophie», Archiv für Geschichte der Philosophie 4(1981): 450-72, y L. Jardine, Francis Bacon, Discovery and the Art of Discourse, cit, pp. 59-65.

${ }^{20}$ Aunque Bacon es poco dado a citar a los autores a los que lee, sin embargo, alude a Ramus en más de una ocasión: una en el Tempus partus masculus (III, 530), en donde lo califica de "peligrosísima carcoma de las letras", y dos en el De Augmentis, la primera para criticar su método dicotómico (IV, 448-9) y la segunda para elogiar la revisión que Ramus hace de las tres reglas aristotélicas (IV, 453). 
Para comprender el significado y alcance de las ideas reformistas de Ramus acerca del modo de entender la dialéctica y la retórica, así como las relaciones entre ambas, es preciso empezar por recordar que, tanto para Aristóteles como para Cicerón, la dialéctica era la teoría de la comunicación culta y la retórica la de la comunicación popular y que, en consecuencia, se consideraba que ambas habían de incluir como partes propias tanto la invención como el juicio, disciplinas a las que la segunda había de añadir también las de la memoria, la elocutio y la actio $^{21}$. A Ramus, como a Agricola, le parece redundante que la consideración de la invención y el juicio haya de hacerse en ambas disciplinas y en consecuencia propone encuadrar esas materias (junto con la memoria) en el ámbito de la lógica y restringir la retórica a la elocución y la acción. Es de este modo como la memoria, concebida ahora como un instrumento para introducir orden en el discurso, se ve convertida en uno de los elementos integrantes de la lógica, marcando esta inclusión el punto de origen de esa concepción del método como algo que desempeña una función ordenadora y clasificatoria en relación con la realidad que tanta importancia había de adquirir en el pensamiento moderno.

Este será el camino que seguirá Bacon en lo que se refiere al tema de la ubicación de la memoria y al papel de la misma dentro del proceso de la comunicación. Para poder entender bien su postura respecto de estas cuestiones, hay que tener presente que el problema de la elección de lugares, de la formación de imágenes y de la disposición de las mismas en un determinado orden ocupa un lugar central en los numerosos tratados que a lo largo de los siglos XV y XVI se dedicaron al tema de la memoria artificial y

\footnotetext{
${ }^{21}$ En De inventione (The Loeb Classical Library, Cambridge, 1949) 1,7.9, Cicerón propone una división de la retórica en cinco partes correspondientes a las cinco officia o tareas que, en el sistema romano, el orador había de satisfacer a la hora de hacer un discurso. Estas tareas eran las siguientes: decidir qué se va a decir (inventio), disponer aquello que se va a decir (dispositio), elegir las palabras adecuadas (elocutio), aprender el discurso de memoria (memoria) y pronunciarlo con la expresión y entonación apropiadas (actio).
} 
que tanto eco habían de tener en la cultura de ese tiempo ${ }^{22}$. Bacon alude a estos tratados cuando, al comienzo del capítulo $\mathrm{V}$ del libro $\mathrm{V}$ de su De augmentis, dedicado al ars reminiscendi, empieza criticando el modo estéril en que se han empleado las técnicas de la memoria y declarando que «al repetir un gran número de nombres o palabras con solo haberlas oído una vez, o componer muchos versos ex tempore sobre un tema, o hacer un símil satírico de lo que ocurre, o convertir una cosa seria en chiste, o buscar peros o contradicciones a todo, o cosas por el estilo (de lo cual las facultades humanas suministran gran abundancia, y tales que con ingenio y práctica pueden ser llevadas a un grado de prodigio extremo), a todo eso no lo tengo en mayor estima que a los juegos de los acróbatas, funámbulos o volatineros» ${ }^{23}$.

Conviene reparar en que lo que Bacon está criticando aquí no son las técnicas de la memoria en cuanto tales, puesto que no deja de señalar que hay "prácticas mejores de ese arte que las acostumbradas "24. Lo que él quiere denunciar son más bien los intentos de reducción de tales técnicas al plano de las artes ocultas y la magia por parte de ciertos tratados que habían empezado a proliferar, tras el resurgimiento del lulismo de finales del siglo XVI, y en los que lo que se pretendía no era ya simplemente recopilar en reglas precisas la función de los lugares y las imágenes para mejorar la capacidad mnemónica, sino describir los lugares y las imágenes, creando una especie de teatro artificial de la realidad. $Y$ es que, en los textos de muchos de los exponentes de la cultura de finales del XVI, ese arte de la memoria que en un principio no era sino un instrumento construido con fines prácticos, aparece ligado a los ideales de la pansofía y a las aspiraciones del lulismo y de la Cábala. Es de este modo como la búsqueda de

\footnotetext{
${ }^{22}$ La enorme importancia y amplitud de este movimiento son analizadas en $\mathrm{F}$. Yates, The Art of Memory, Londres, 1966, y también en P. Rossi, Clavis Universalis, México, FCE, 1989.

${ }^{23}$ Works, IV, 436.

${ }^{24}$ Ibid.
} 
una "clave universal" capaz de descifrar el "alfabeto del mundo" y la aspiración a construir un "teatro del mundo" que fuera un reflejo de la realidad hacen de las técnicas de la memoria artificial algo al servicio de fines muy distintos a aquellos para los que en un principio habían sido creadas, y es también de este modo como los meros intentos de elaborar con instrumentos racionales técnicas basadas en el estudio de las asociaciones mentales, presentes en los primeros tratados dedicados a este arte, devienen un complejo simbolismo cuya finalidad es encubrir una sabiduría oculta a la que sólo puede llegarse a través de la apelación a símbolos e imágenes.

Es justamente de toda esta corriente de pensamiento, representada por autores como Giulio Camillo el Delminio, Cosma Rosselli, Giambattista della Porta o Giordano Bruno, en la que el arte de la memoria ya no es una técnica ligada a las finalidades del discurso retórico sino un instrumento que puede servir para construir un edificio cuyas estructuras constituyan el reflejo de las relaciones que forman la trama del universo, de la que Bacon deseaba distanciarse a toda costa. Prueba de ello son los diversos textos en los que el Lord Canciller arremete contra el método luliano al que acusa de ser un método «de impostura» ${ }^{25}$. Pero esto no quita para que en el alegato baconiano en favor de la creación de un sistema de signos que sean un fiel reflejo de la realidad (lo que él denominará caracteres reales), fuente a su vez de todos los intentos de creación de lenguajes universales o filosóficos que siguieron, se escuche el eco de esta idea luliana de un arte capaz de presentarse como "clave" de la realidad. Este alegato lo introduce Bacon precisamente en el curso de su discusión del arte de la comunicación y de los signos que la hacen posible, poco después de haber abordado el tema de la memoria. Allí, tras observar que, en su sentido más amplio, la comunicación no es coextensiva con el habla, sino que «tiene algunos otros hijos además de la palabras y

${ }^{25}$ Cf., por ejemplo, Works IV, 454. 
las letras ${ }^{26}$, afirma Bacon que los unidades formales de la comunicación no se reducen a los signos verbales, sino que también hay signos no-verbales - «notas de las cosas"- que tienen significado "sin la ayuda o intervención de las palabras». Algunos de esos signos - dice- son «ex congruo, donde el signo tiene alguna congruencia con la idea», otros son «ad placitum, donde el signo es adoptado y consensuado a voluntad ${ }^{27}$. Entre los signos del primer tipo incluye los gestos y los jeroglíficos, siendo un rasgo común a ambos el tener alguna similitud con la cosa simbolizada, es decir, el ser una especie de emblemas. Entre los consensuados, destaca los caracteres chinos, de los que dice que son caracteres no nominales sino reales por cuanto que se trata de

caracteres que no representan letras o palabras, sino cosas e ideas, hasta el punto de que algunas naciones cuyas lenguas son totalmente distintas, pero que están de acuerdo en el uso de tales caracteres (los cuales tienen un mayor área de difusión entre ellas) se comunican entre sí mediante la escritura en tal medida que cualquier libro escrito en caracteres de esta índole puede ser leído por.cada nación en su propia lengua ${ }^{28}$.

Los sistemas de escritura chinos, que eran conocidos en aquel tiempo gracias a la Historia del gran Reino de la China de Juan González de Mendoza y a la publicación de los diarios del Padre Mathew Ricci por N. Trigault, tenían, para los hombres del siglo XVII, algunas características que hacían de ellos modelos a imitar: estaba su gran inteligibilidad, pero estaba sobre todo el hecho de que se trataba de lenguajes en los que los caracteres guardan una relación directa con las cosas simbolizadas. Si estos sistemas no llegaron a revelar un método concreto conforme al cual poder

\footnotetext{
${ }^{26}$ Works, IV, 439.

27 Ibid.

${ }^{28}$ Ibid.
} 
construir lenguajes universales debido al inconveniente del elevadísimo número de caracteres que eran necesarios y a la dificultad que entrañaba su uso y aprendizaje, al menos desempeñaron el importante papel de llamar la atención de Bacon sobre la posibilidad de establecer lenguajes de caracteres reales para uso universal. Por qué un lenguaje como éste constituía para él el ideal de lenguaje y de qué modo este ideal se convirtió en guía para la construcción de sistemas de notación que se suponían ser un reflejo de la realidad son temas que, por lo demás, no podremos entender del todo sin tomar en consideración, además de esta deuda de su pensamiento para con la tradición del arte de la memoria, sus ideas acerca del lenguaje en general y sus pronunciamientos en favor de la necesidad de un estilo claro y desprovisto de florituras retóricas cuando de transmitir el saber se trata.

\section{4.}

La actitud que Bacon mantiene hacia el lenguaje arranca de su convicción de que, al igual que otras manifestaciones del espíritu humano, el lenguaje, aunque un instrumento del que no se puede prescindir, constituye un obstáculo que se interpone entre el entendimiento y la realidad, dificultando la comprensión de ésta. Considera Bacon que los idola fori, que es como denomina a este tipo de errores que se deslizan en el entendimiento por causa de las palabras, constituyen el mayor obstáculo para el progreso del conocimiento, pues si bien «los hombres creen que su razón gobierna las palabras, ocurre también que las palabras imponen su ley al entendimiento, siendo esto lo que ha convertido en sofísticas e inactivas a la filosofía y a las ciencias ${ }^{29}$. Dos son los tipos de tales errores que, en su opinión, hay: 0 "son nombres que resultan de suposiciones fantásticas a las que no corresponde nada en la

${ }^{29}$ NO I, 59. 
realidad" o son "nombres de cosas que existen, pero confusos y mal definidos» y «están extraídos de la realidad de un modo precipitado y sin las debidas comprobaciones ${ }^{30}$. Los del primero de estos dos tipos, entre los que incluye «la fortuna, el primer motor, las órbitas planetarias, los elementos del fuego y otras invenciones por el estilo que tiene su origen en teorías falsas y vanas", son fáciles de desterrar, pues para ello basta con desechar las teorías en cuestión. En cuanto a los del segundo tipo, son en su opinión mucho más difíciles de erradicar, como se desprende de la consideración que hace de la palabra "húmedo". Esta

no es más que un signo vaga y confusamente aplicado para denotar una variedad de acciones que no se prestan a ser reducidas a un significado constante, pues significa tanto aquello que se derrama en torno a otro cuerpo como aquello que es por sí mismo indeterminado y no puede solidificarse; lo que cede fácilmente en cualquier dirección y lo que se divide y esparce fácilmente; lo que se junta y recoge fácilmente y lo que fluye y se pone en movimiento sin dificultad. De donde se sigue que, cuando uno se dispone a aplicar la palabra, si lo hace en un sentido resulta que la llama es húmeda; si en otro, que el aire no es húmedo; si en otro, que el polvillo fino es húmedo; si en otro, que el vidrio es húmedo. De ahí que no sea difícil ver que esta noción ha sido abstraída a partir únicamente del agua y algunos otros líquidos comunes y corrientes, sin la debida verificación ${ }^{31}$.

Esta insistencia en la necesidad de estar alertas frente a los peligros del lenguaje y a los muchos pseudoproblemas a que los embrollos terminológicos pueden dar lugar marca el inicio de una

\footnotetext{
${ }^{30}$ NO I, 60. A la caracterización de estos prejuicios que impiden llegar a la interpretatio naturae, o idola, de los que Bacon distingue cuatro tipos, están dedicados los aforismos 38-92 de la primera parte del Novum Organum, pero también se alude a ellos en Works, III, 241, 245, 394, 536, 548; y IV, 431.

${ }^{31}$ NO, I, 60.
} 
actitud y unas ideas acerca del mismo que, si bien no puede decirse que se confinen a suelo inglés, no cabe duda de que es allí donde van a encontrar su más acabada expresión durante todo este siglo XVII. Con esta actitud, Bacon animó a los representantes de la nueva ciencia a considerar la reforma del lenguaje y del estilo tan esencial como la propia reforma de la ciencia, a formular sus ideales estilísticos y a tratar de hacerlos operativos; se convirtió, en suma, en el adalid de un estilo de expresión para la ciencia que habría de encontrar multitud de adeptos, especialmente entre los primeros miembros de la Royal Society, muchos de los cuales adoptaron como propio el diseño que Bacon había hecho de lo que él creía el estilo más adecuado para ella. En muchos de ellos encontramos, en efecto, no sólo una crítica del lenguaje sino también una reafirmación de esta postura en contra de la retórica y en favor de un estilo claro y conciso. Este es, por ejemplo, el caso de Robert Boyle, quien en el prefacio que escribió para sus Physiological Essays (1661), después de manifestar sus preferencias por el ensayo declaraba que, en lo que al estilo se refería, él se había esforzado por

escribir en un estilo filosófico más bien que retórico, movido por el deseo de que mis expresiones sean claras y significativas más que artificiosamente adornadas...y desde luego, en esos discursos en los que nuestro objeto es sólo informar a los lectores, y no deleitarles ni persuadirles, la claridad debe ser valorada al menos como una de las cualidades del estilo; y adoptar innecesarios ornamentos retóricos para registrar un experimento o explicar algo de naturaleza abstrusa no sería tan inadecuado como sería (para quien decide no mirar directamente el sol) pintar los lentes de un telescopio, cuya claridad es su razón de ser y en los que hasta los más maravillosos colores más que agradar al ojo lo que harían sería impedir la vista ${ }^{32}$.

${ }^{32}$ R. Boyle, Works I, p. 300. Citado en English Science, Bacon to Newton, ed. de B. Vickers (Cambridge University Press) 1967, p. 10. 
El de la reforma del lenguaje es un tema que preocupa tanto a los llamados « baconianos vulgares», más interesados en la ciencia como un medio para conseguir un desarrollo material y tecnológico y como instrumento para lograr la reforma social y religiosa, como a los «baconianos puros», interesados más bien por desarrollar una actividad intelectual con el fin primordial de contribuir al desarrollo del conocimiento. A estos últimos, este tema les preocupa sobre todo porque creen que sin un instrumento de comunicación claro y eficaz no puede progresar el conocimiento. No tiene nada de extraño, pues, que sea uno de los temas centrales de la History of the Royal Society, de Thomas Sprat, en la que supuestamente se recogen las inquietudes e intereses de los primeros miembros de la Royal Society. En esta obra, escrita precisamente por instigación de J. Wilkins, repite Sprat argumentos tomados del Avance del saber acerca de la conveniencia de un estilo claro y conciso y de la necesidad de evitar metáforas, imágenes y toda clase de formas de embellecimiento verbal, más propias, dice, de la infancia del lenguaje que de la edad de la razón en la que acaba de entrarse tras los excesos de la guerra. Sprat espera que esta tarea de reforma sea uno de los cometidos que emprenda la Royal Society, la cual por lo pronto habría impuesto ya a sus miembros, afirma dejándose llevar por el entusiasmo, «una forma de hablar cercana, desnuda, natural; expresiones positivas; sentidos claros; una facilidad innata: acercar todas las cosas a la claridad matemática tanto como se pueda y preferir el lenguaje de los artesanos, campesinos y comerciantes al de la gente culta y erudita» ${ }^{33}$. Pero si semejante declaración dista mucho de ser un fiel reflejo de la realidad, toda vez que de hecho los miembros de la Royal Saciety no sólo no abjuraron de las metáforas y demás figuras retóricas sino que siguieron empleándolas, especialmente cuando de atacar a sus rivales o de defenderse de los ataques de éstos se trataba, los alegatos baconianos en favor de un estilo claro y conciso no pasan tampoco de ser más que meras manifestaciones

${ }^{33}$ T. Sprat, The History of the Royal Society, 1687, p. 113. 
de un desideratum. Esto es lo que se desprende de la simple consideración de su estilo prosístico, que ha sido objeto de algunos interesantes estudios, todos los cuales coinciden en señalar cómo Bacon, como buen hombre del Renacimiento que era, pensaba en imágenes, hasta el extremo de que éstas no se limitan a acompañar a su pensamiento, sino que parecen incluso adelantarse a él y determinarlo ${ }^{34}$, cosa que ha llevado a alguno a sugerir que tal es el estilo de aprehensión que puede llamarse poético, haciendo buena la afirmación de Shelley de que en el fondo «Lord Bacon era un poeta» ${ }^{35}$.

Esta creciente sensación de insatisfacción ante los lenguajes naturales fue, con todo, uno de los factores que más contribuyó a crear un clima favorable para la constitución de lenguajes perfectos. Ya Descartes, en carta a Mersenne, hablando de las ventajas que tendría un lenguaje filosófico de poder ser construido, cosa que él dudaba, afirmaba que un lenguaje así «ayudaría al juicio, representando todas las cosas de modo tan distinto que sería imposible equivocarse; al contrario de lo que sucede con las palabras que tenemos, que prácticamente no tienen más que significados confusos, a los que el espíritu humano se ha acostumbrado desde hace tiempo, siendo ésta la causa de que no entienda bien casi nada ${ }^{36}$. También J. Wilkins acompaña la exposición de su esquema de lenguaje universal de una exhaustiva crítica de los muchos defectos inherentes a todos los lenguajes existentes, incluidos el latín y el chino ${ }^{37}$.

Pero el reconocimiento de la conveniencia de evitar la vaguedad y ambigüedad de las palabras, la abundancia de sinónimos, las

\footnotetext{
${ }^{34}$ El tema del estilo prosístico de Bacon es abordado en B. Vickers, Francis Bacon and Renaissance Prose (Cambridge University Press, 1968); en cuanto a su influencia en la prosa inglesa posterior, véanse los diversos ensayos reunidos por R.F. Jones en The Seventeenth Century (Stanford, 1951), especialmente "Science and English Prose Style in the third quarter of the Seventeenth Century", Pp. 75-110.

${ }^{35}$ Cf. Vickers, op. cit.

${ }^{36} \mathrm{R}$. Descartes, Oeuores Completes, ed. a cargo de C. Adams y P. Tannery, 12 vols., París 1897-1910, 1, p. 76.

${ }^{37}$ Essay, pp. 17-18.
} 
anomalías e irregularidades de sus construcciones gramaticales y demás defectos inherentes a cualquier lenguaje natural no fue el único móvil que incentivó la creación de lenguajes universales. Aunque muchas veces se olvida, los esquemas de escritura universal y de lenguaje filosófico del siglo XVII, como ha escrito uno de sus estudiosos, «surgieron no sólo de actitudes que eran condenatorias de los lenguajes existentes, sino también de un intenso deseo de forjar una relación nueva y más directa entre palabras y objetos» ${ }^{38}$. Y es que si los lenguajes existentes eran insatisfactorios a los ojos de quienes se sintieron llamados a la tarea de construir lenguajes universales, no lo eran sólo por los defectos antedichos, sino también y ante todo porque ninguno de ellos guardaba una relación estrecha con la realidad material, con el consiguiente efecto de no facilitar el acceso al "conocimiento real". Este supuesto defecto ya había sido señalado por algunos de quienes se habían destacado en la defensa de la reforma de la enseñanza del latín, lengua que no sólo tampoco servía para comunicarse con los habitantes de los mundos recién descubiertos sino que era tan defectuosa como las demás en este punto. Uno de los que más habían descollado en este campo, Comenius, a cuyo tratado Janua linguarum ya antes he aludido, escribía, por ejemplo:

El estudio de los lenguajes especialmente entre los jóvenes debe vincularse a los objetos, de suerte que nuestra familiaridad con el mundo objetivo y con el lenguaje, esto es, nuestro conocimiento de los hechos y nuestra capacidad de expresarlos puedan progresar parejamente. Pues son hombres lo que estamos formando y no papagayos... De donde se deduce, primero, que no deben aprenderse las palabras al margen de aquello a lo que se refieren, ya que los objetos no existen separadamente y no pueden ser aprehendidos sin las palabras, sino que ambas cosas existen y realizan sus funciones juntas ${ }^{39}$.

38 Knowlson, Universal Language schemes in England and France 1600-1800, p. 36.

${ }^{39}$ Didactica Magna, cit. en la traducción de M.W. Keatinge, Comenius, London, 
Es esta idea de que la reforma del lenguaje es inseparable de la descripción sistemática de la realidad y de que la construcción de un lenguaje de caracteres y el establecimiento de una taxonomía son tareas que corren parejas la que constituirá el impulso definitivo para los proyectos de mediados del XVII.

5.

La experiencia de los primeros inventores de escrituras comunes había puesto de relieve que las principales dificultades que entrañaba la realización de semejante proyecto eran, de un lado, el enorme número de signos requeridos y, de otro, el modo de disponer las palabras de suerte que fuese posible recordarlas. La solución parecía obvia: una clasificación sistemática de las cosas que permitiera una simbolización adecuada de las mismas. A mediados del siglo XVII se produce, en palabras de uno de los primeros estudiosos del tema, «un tránsito de la convicción de que un esquema satisfactorio para un nuevo lenguaje se puede tomar de un lenguaje antiguo [el hebreo] a la creencia de que semejante esquema ha de extraerse de una descripción correcta del orden de la realidad ${ }^{40}$. Por esta época, la mayor parte de los constructores de lenguajes filosóficos habían llegado, en efecto, a asumir que el nuevo lenguaje había de basarse en términos técnicos, entendiendo por tales términos construidos de tal modo que indicaran sin ambigüiedades las diversas cualidades de los objetos que representaban: William Petty estaba entregado a la construcción de un lenguaje botánico que transmitiera por medio de sus símbolos ciertas propiedades de hierbas y plantas, Seth Ward estaba buscando el modo de extender este procedimiento a la simboliza-

1931, pp. 171-2.

${ }^{40} \mathrm{De}$ Mott, «The Sources and Development of John Wilkins' "Philosophical Language"", p. 2. 
ción de la totalidad del conocimiento humano y John Wilkins, en parte siguiendo esta sugerencia de Seth Ward y en parte como consecuencia de su participación en el proyecto de Dalgarno, había asumido la hipótesis de que una de las principales tareas que había que afrontar, para poder construir un lenguaje universal, era la preparación de tablas en las que se pudieran clasificar objetos e ideas conforme a sus rasgos distintivos.

Aunque es sumamente probable que esta idea de construir un vocabulario que indique las propiedades de las cosas simbolizadas como requisito previo a la simbolización tenga más de una fuente, una de las no menos importantes fue casi con toda certeza la de la simbolización y sistematización del conocimiento practicadas por lulistas , cabalistas y autores integrados en la larga tradición del arte de la memoria. Frances Yates, cuyo renombre como historiadora de las ideas ocultas en la época isabelina es sobradamente conocido, escribió que los esfuerzos del XVII por construir un lenguaje universal «surgieron directamente de la tradición de la memoria con su búsqueda de signos y símbolos susceptibles de ser empleados como imágenes mnemónicas" ${ }^{11}$. Una de las principales funciones de la representación simbólica de las ideas era sin duda la de permitir memorizar más fácilmente las cosas, y esta función es una de las que más interesó a los constructores de lenguajes universales. La mayor parte de ellos destacaron el valor mnemónico de sus construcciones, convencidos como estaban de la inutilidad de un lenguaje que no fuera fácil de aprender y retener ${ }^{42}$. Y es que si organizar las "palabras" del nuevo lenguaje en grupos clasificados era un modo de reducir el número de signos requeridos, era también una forma eficaz de resolver algunas dificultades relativas a su aprendizaje y memorización. Es sumamente probable

${ }^{41}$ F. Yates. The Art of Memory, p. 378.

42 Mersenne en carta a Peiresc destaca las virtudes mnemónicas de su idiome universel (Correspondence 5, p. 136). Dalgarno afirma que de su Ars Signrum podía inferirse un arte de la memoria más asequible que cualquiera de los conocidos (cit., en Knowlson, op. cit , p. 81) y en cuanto a Wilkins, destaca también el valor mnemónico de su lenguaje filosófico (Essay, p. 22) 
por tanto que los constructores de lenguajes universales, que consideraban la ordenación de las ideas como un requisito previo, hallaran su inspiración en la práctica de los autores del arte de la memoria, práctica consistente, como antes hemos visto, en la elección de lugares, la asignación a los mismos de imágenes representativas de las cosas que habian de recordarse y su disposición en un orden conocido ${ }^{43}$. Pruebas de esta influencia no faltan, pero tal vez la más contundente sea la estructura exhibida en general por los últimos esquemas y más en concreto por el de J. Wilkins, en el que la elección de un número fijo de especies dentro de cada género y de un número determinado de plantas bajo cada diferencia, así como el apareamiento de ciertas especies y diferencias no hacen sino reflejar la importancia conferida por este autor al aspecto mnemónico de su trabajo, importancia que le llevó a veces a la imposición de un orden artificial que suscitó grandes reparos por parte de su más estrecho colaborador, el afamado naturalista John Ray ${ }^{44}$.

Pero detrás del intento de clasificar y sistematizar todo el saber humano con objeto de poder llegar a la representación simbólica que los constructores de lenguajes universales pretendían no parece que lata tan sólo la tradición del ars memorativa sino también la mucho más amplia y compleja del lulismo y la Cábala.

${ }^{43} \mathrm{~F}$. Yates cree que el modo de disponer el material en un orden en los tratados de la memoria tiene algo en común con el método dialéctico de Ramus de descenso de géneros a especies. De ahí las similaridades que existen entre el arte clásico de la memoria, la noción ramista de "orden dialéctico" y las clasificaciones de los tratados sobre lenguajes filosóficos. Cf. The art of Memory, p. 233.

44 John Ray se lamentaba así de las dificultades de hacer encajar a la naturaleza en el molde impuesto por Wilkins: «En la elaboración de estas tablas, no me es preciso seguir las órdenes de la naturaleza, sino adaptar las plantas al sistema mismo del autor. Debo dividir las hierbas en tres clases que sean lo más posible iguales, subdividir después cada clase en diferencias, atendiendo a que las plantas ordenadas en cada díferencia no superen determinado número fijo... ¿Quién podría esperar que un método tal fuese satisfactorio? Este parece absurdo y muy imperfecto; debo decir que se trata de un método absurdo porque atribuyo más valor ala verdad que a mi reputación personal» (Carta a Lister, The Correspondance of John Ray, Londres, 1848, pp. 41-42 cit. P. Rossi, Clavis universalis, p. 205. Sobre estas reservas, véase B. De Mott, «Science versus Mnemonics: Notes on John Ray and on John Wilkins'Essay", Isis 48 (1957): 3-12. 
Como antes he señalado, en su Ars brevis, en su Ars inventiva y en algunas otras obras, $R$. Lull había tratado de diseñar un arte universal que fuera la clave para la comprensión del universo. Era creencia común a lulistas y cabalistas que la práctica de este arte, basado en la combinación de letras que representaban los atributos divinos, dignitates Dei, llevaría a la comprensión de la verdadera naturaleza del universo. Pues bien, si es un hecho innegable que en los proyectos de lenguajes perfectos este simbolismo oculto ha sido reemplazado por un lenguaje basado en una enumeración más racional y "científica" de las propiedades de los objetos, derivado de una clasificación conforme a género, especie y diferencia específica, no es menos cierto que algunas de las ideas mantenidas por sus creadores, y en concreto la de que los símbolos han de guardar una relación directa con la realidad, revelan un cierto parentesco entre un arte de carácter decididamente religioso y oculto y estos esquemas etiquetados de "científicos". La obra de Lull, de sus comentaristas y difusores fue no sólo conocida sino incluso explícitamente relacionada con sus tareas por algunos de estos autores del siglo XVII. Así, por limitarme a señalar un solo ejemplo, Seth Ward, en su Vindiciae Academiarum, obra en la que diseña las líneas generales del lenguaje filosófico construido por Wilkins, tras afirmar que el uso de símbolos no se ha confinado históricamente a las matemáticas sino que ha sido aplicado «a la naturaleza de las cosas» por los cabalistas «que han hecho símbolos de las letras del alfabeto», manifestaba su confianza en que un lenguaje de caracteres reales «proveerá de aquello que los cabalistas....han buscado vanamente en el hebreo" ${ }^{45}$.

El problema de cómo ciertas ideas procedentes del lulismo y la Cábala entran en la corriente de pensamiento del XVII y se transfor-

45 Esta obra, publicada en 1654, fue escrita en respuesta al duro ataque que Webster, un filósofo hermético pero partidario del método experimental, había lanzado en su Academiarum examen contra el mundo académico. La edición facsímil de ambas obras, la primera de las cuales va precedida de un prólogo de Wilkins, puede hallarse en A. Debus, Science and Education in Seventeenth Century: The Webster-Ward Debate, New York Science History Publications, 1970. El texto citado es de Vindiciae Academiae, pp. 19-22 del original. 
man en otra cosa distinta es un importante problema que excede los límites de este trabajo en el que sólo se pretende subrayar el destacado papel desempeñado por Bacon en la transmisión y transformación de esta vieja pretensión de comprender la realidad a través de la lectura del alfabeto divino en el proyecto, si no imposible al menos sí igual de impracticable, de construir lenguajes que guarden una relación isomórfica con un modelo de la naturaleza. Bacon es la fuente de inspiración de la que los constructores de lenguajes filosóficos no sólo toman la idea de un sistema de escritura no-alfabética, sino también la de que este sistema de escritura ha de basarse en una clasificación adecuada de la naturaleza. Bacon pensaba, en efecto, que el lenguaje y el modelo de la naturaleza han de ser isomórficos, pues a menos que las palabras representen la verdadera naturaleza de las cosas, no podrá haber comunicación verdadera. Es de este modo como la reforma del lenguaje por él propuesta entronca directamente con su modo de entender el método científico y con su idea de que el objetivo de la ciencia es el descubrimiento de las formas o de las naturalezas simples de que se componen todas las cosas.

La influencia del pensamiento baconiano en este movimiento del siglo XVII no se limita, pues, a su concepción "materialista» del lenguaje y al destacado papel que ésta desempeñó en la creación de un clima de sospecha hacia el lenguaje. Va bastante más allá de esto. Bacon es también una de las correas de transmisión entre este movimiento y ciertas fuentes más "ocultas" a las que sin duda hay que remontarse si se quieren explicar sus orígenes. En el pensamiento de este autor late aún la creencia de que ha de haber una relación directa entre el lenguaje y la realidad y es esta creencia, a la que por lo demás parece responder ese hincapié en las imágenes que tanta fuerza e intensidad confiere a su estilo prosísti$\mathrm{co}^{46}$, la que subyace a la convicción de los constructores de

${ }^{46}$ El trabajo de B. Vickers antes citado tiene la limitación, por lo demás deliberada, de moverse en un terreno puramente literario, dejando sin explicar a qué se deben ciertas opciones estilísticas del autor estudiado. Así, tras señalar que Bacon insinúa que hay analogías entre las cosas, en las que se detecta la 
lenguajes filosóficos de que, para poder llegar a una simbolización icónica adecuada de cada categoría, antes es preciso alcanzar otra meta: una categorización exhaustiva de la realidad, un sistema taxonómico perfecto el universo.

La convicción de que a través de este procedimiento taxonómico y por ende empírico, se puede lograr conocer el orden de la naturaleza no tardaría, como es bien sabido, en entrar en quiebra y en ser suplantada por la idea de que, para poder penetrar en los secretos de la naturaleza hace falta echar mano de instrumentos más poderosos, como es el caso de los métodos matemáticos. El no haber visto esto es, como tantas veces se ha señalado, uno de los mayores escollos del pensamiento baconiano y de su concepción del método científico. Por lo demás, el empecinamiento en lograr lenguajes que fueran un puro calco de la realidad tal vez explique también el hecho de que estos autores no lograran tampoco vislumbrar el papel potencial de semejantes construcciones como instrumentos para el pensamiento lógico y exacto. Hay una única excepción, y es la de Seth Ward, autor que no sólo vincula explícitamente la búsqueda de lenguajes universales con el desarrollo de notaciones algebraicas, cosa que también habían hecho Dalgarno o Boyle, sino que además se muestra totalmente consciente del valor "calculístico", o como él lo expresa, de la capacidad para "realizar demostrativamente discursos exactos» que un sistema así podría llegar a alcanzar ${ }^{47}$. Tal vez no sea casual que este autor sea también el único de entre ellos en lamentar que «my Lord Bacon» no fuera más experto en matemáticas ${ }^{48}$, cosa que, efectivamente, dada la enorme influencia que ejerció no podemos dejar de lamentar todos.

unidad de la naturaleza, Vickers añade: «Enfrentado con este semi-místico concepto de analogía en tanto que fuerza creadora del universo, el crítico literario se ve forzado a retirarse, destacando sólo que, una vez más, Bacon parece haber adoptado una forma estilística tradicional (como ocurría en el caso del aforismo) y haberla aplicado a muy especiales y ocultos propósitos", op. cit., p. 154.

47 Vindiciae Academiarum, p. 21 (p. 215 de A. Debus, op. cit.).

${ }^{48}$ Ibid., p. 25 (p. 219 de A. Debus, op. cit). 